\title{
Net Aerial Primary Productivity Models for Alfalfa Varieties (Medicago sativa L.) Derived from the Red Vegetation Index
}

\author{
By Jose Luis Tiedemann ${ }^{*}$
}

\begin{abstract}
The present study is aimed at quantifying and comparing the net aerial primary productivity (NAPP) of two alfalfa varieties (Medical sativa L.) by determining the Radiation Use Efficiency (E) for each variety, estimating the NAPP though the Red Vegetation Index and relating it to the quantified NAPP. Significant differences between the individual NAPP of each variety were not found: G969 $=1564 \mathrm{~g} \mathrm{dm} \mathrm{m}^{-2}$ and $M 901=1636 \mathrm{~g} \mathrm{dm} \mathrm{m}^{-2}(T=0.92 ; p>0.05)$. The $\mathcal{E}$ of the G969 was $0.56 \mathrm{~g} \mathrm{Mj}^{-1}$ while that of M901 was $0.58 \mathrm{~g} \mathrm{Mj}^{-1}$. Significant direct relationships between the quantified NAPP and that calculated using the Red Vegetation Index were found. The models obtained were: $N A P P_{G 969}=506.06 x-$ $343.25\left(R^{2}=0.88 ; p<0.001\right)$ and $N A P P_{M 901}=420.28 x+37.82\left(R^{2}=0.98\right.$; $p<0.001)$. The $\varepsilon$ values of the alfalfa varieties under study, determined at local level, reduce uncertainty when generating predictive models of productivity. The NAPP of alfalfa varieties can be non-destructively predicted using the Red Vegetation Index obtained by a reflex $R G B$ digital camera.
\end{abstract}

Keywords: radiation use efficiency, digital camera, canopy reflectance, $R G B$ indices

\section{Introduction}

Determining the net aerial primary productivity of the green vegetation in cattle raising activities is fundamental to make a decision at site level, particularly in assigning areas and managing grazing lands and livestock. The traditional measuring techniques, particularly the destructive ones (i.e., biomass harvesting or clipper, rising plate meter, compressed sward height, or a meter stick) are not only time consuming and increase costs but also highly tedious especially when the sampling area is increased (Gruner et al. 2019). Consequently, the spectral information supplied by remote sensing may provide a rapid and inexpensive means of estimating forage biomass and quality variables (Zhao et al. 2007, Gruner et al. 2019). In agriculture, there has been a rising demand in remote sensing due to its capabilities for collecting data involving less time, less labor and minor impact on the fields (Costa et al. 2020).

The Vegetation Index obtained from remote as well as near sensing, represents a combination or a filtering process of multiple spectral data sets to create a single value for each point in an image usually generated by a mathematical model (McKinnon and Hoff 2017). It is a good indicator of the ability for vegetation to absorb photo-synthetically active radiation and has been widely used by researchers

*Professor, Faculty of Forest Science, National University of Santiago del Estero \& Faculty of Natural Sciences, National University of Salta, Argentina. 
to estimate green biomass. The close relationship between the net aerial primary productivity (NAPP) and the Vegetation Index made their use as potential productivity indicators possible (Tucker 1979). It was done using the Monteith's empirical model (1977) based upon the Radiation Use Efficiency (RUE $=\varepsilon$ ) which is a useful tool for quantifying the seasonal biomass production without limitations of water, temperature or fertility.

Digital cameras, commercially accessible and available, are effective alternatives for estimating biophysical parameters (biomass and leaf area index) in a non-destructive way (Przeszlowska et al. 2006). They can be considered as proxy detection sensors of high spatial and time resolution, with a Cartesian system for capturing colors in the space, that is, red (R), green $(G)$ and blue (B), where the RGB digital numbers provide a permanent and repeatable register of the plots at low cost and with high accuracy (Sonnetag et al. 2011, Sakamoto et al. 2012, Lussem et al. 2018). The intensity of the green and red reflectance becomes efficient choices to determine biophysical properties in agricultural crops (Gitelson et al. 2002). In this sense, either the Color or the Vegetation Indices synthetizes the information concerning the RGB brightness obtained by using digital cameras (Sonnetang et al. 2011). Several plant indices were created using just conventional RGB channels to make data collection more accessible (Costa et al. 2020).

Among the studies carried out using digital cameras it is worth mentioning those by Przeszlowska et al. (2006), which assessed the accuracy, precision, and relative labor costs of the traditional leaf area meter method and various indirect methods for measuring Green Area Index (GAI) on shortgrass prairie. GAI measured with a standard leaf area meter was compared to: 1) spectral vegetation indices calculated from multispectral radiometer data, 2) GAI obtained from laser point-frame measurements, and 3) green cover estimates derived from digital camera images. Ge et al. (2016) stated direct relationship between the $2 \mathrm{G} /(\mathrm{B}+\mathrm{R})$ index and the estimated green area $(r=0.95)$, green matter $(r=0.99)$ and dry matter $(\mathrm{r}=0.95)$ of corn (Zea mays). They concluded that the area estimated using the index and related to destructive measurements is a good estimator of green matter, dry matter and leaf area in early vegetative states $(\mathrm{r}=0.95)$. Jáuregui et al. (2018), using canopy software, related light interception and the NAPP in alfalfa crops by the R/G, B/G and 2G-R-B Vegetation Index and reported the coverage percentage or foliage green area index. They obtained significant direct relationships in spring and summertime $\left(\mathrm{R}^{2}=0.86 ; \mathrm{p}<0.05\right)$ and in fall and wintertime $\left(\mathrm{R}^{2}=0.77 ; \mathrm{p}<0.05\right)$.

Based on the above and tending to get local information, this study aims at quantifying the net aerial primary productivity of two varieties of alfalfa (Medicago sativa L.), determining the Radiation Use Efficiency in each variety, estimating the NAPP using the Red Vegetation Index derived from the digital camera, and relating it to the quantified NAPP. 


\section{Methodology}

Study Area

The test was carried out at the Silviculture and Forest Management Institute (Lat -27.88; Long -64.25), Forest Sciences Faculty (FCF), National University of Santiago del Estero (UNSE), located at El Zanjon, Province of Santiago del Estero, Argentina (Figure 1).

Figure 1. Left: Argentina and the Province of Santiago del Estero (in Gray) Center: Province of Santiago del Estero and El Zanjon (Red Star) Right: Test Location (Red Circle), the Silviculture and Forest Management Institute, FCF, UNSE (Lat -27.88; Long -64.25)

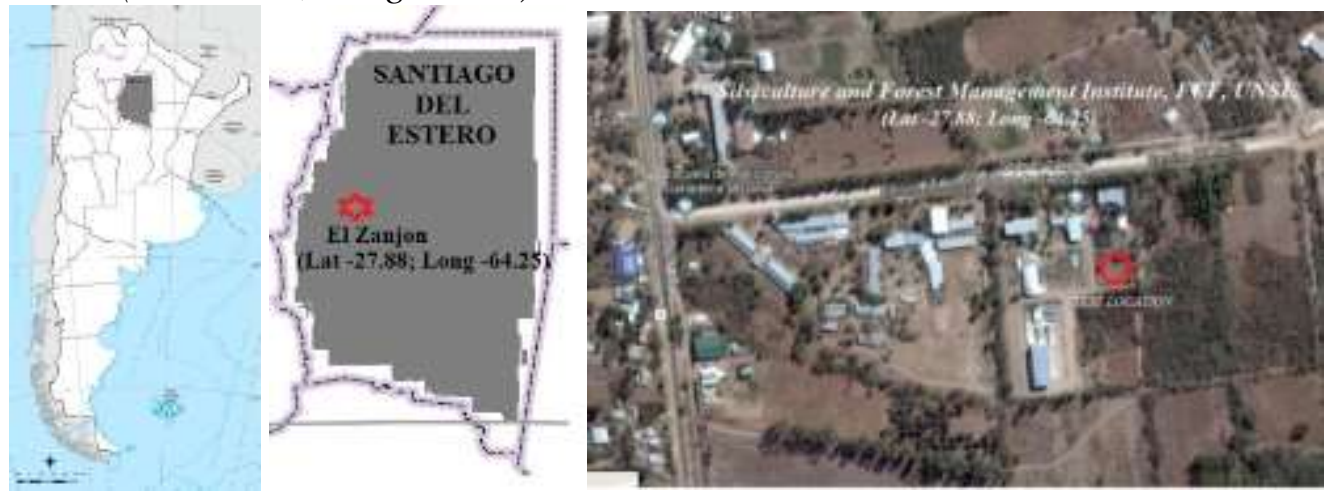

Source: The National Geographical Institute and Google Earth.

The climate data of the area under study (Table 1) was provided by Santiago del Estero Aero Station (Lat -27.76; Long -64.32) of the Weather Information Center of the National Weather Service (2020).

Table 1. Climate Variables of the Area under Study Correspond to 2018-2019, being TMED: Mean Temperature, PPMEAN: Mean Precipitation, EVT-P: Potential Evapotranspiration and HR: Relative Humidity

\begin{tabular}{|l|c|c|c|c|c|}
\hline $2018-2019$ & $\begin{array}{c}\text { TMED } \\
{ }^{\circ} \mathrm{C}\end{array}$ & $\begin{array}{c}\text { PPMEAN } \\
\mathrm{mm}\end{array}$ & $\begin{array}{c}\text { EVT-P } \\
\mathrm{mm} \mathrm{day}^{-1}\end{array}$ & $\begin{array}{c}\text { Wind } \\
\mathrm{Km} \mathrm{h}^{-1}\end{array}$ & $\begin{array}{c}\text { HR. } \\
\%\end{array}$ \\
\hline AUG & 14.39 & 2 & 2.12 & 5.96 & 54.3 \\
\hline SEP & 21.72 & 12.30 & 3.56 & 6.17 & 50.90 \\
\hline OCT & 22.11 & 44.70 & 3.59 & 4.93 & 54.80 \\
\hline NOV & 25.04 & 66.7 & 5.02 & 6.51 & 59 \\
\hline DEC & 26.05 & 114.2 & 5.16 & 5.64 & 62.7 \\
\hline JAN & 26.57 & 134.8 & 4.97 & 5.06 & 66.8 \\
\hline FEB & 24.79 & 100.6 & 4.61 & 4.62 & 70 \\
\hline MAR & 24.84 & 91.1 & 4.67 & 3.68 & 74.2 \\
\hline APR & 20.43 & 35.9 & 2.62 & 3.16 & 76.6 \\
\hline MAY & 16.33 & 17.2 & 4.90 & 2.61 & 74.5 \\
\hline JUN & 13.31 & 6.6 & 5.13 & 2.75 & 73.2 \\
\hline JUL & 12.69 & 3 & 4.32 & 3.63 & 63.6 \\
\hline
\end{tabular}


The soil of the study area is Torriortentic Haplustoll with A1, AC C1 and IIC2 horizons, without depth and drainage limitations (Angueira 2015). Table 2 shows modal soil profile (Lat -27.864; Long-64.219).

Table 2. Modal Soil Profile of the Area under Study

\begin{tabular}{|l|c|c|c|c|}
\hline Horizon & $\mathrm{A} 1$ & $\mathrm{AC}$ & $\mathrm{C} 1$ & $\mathrm{IIC} 2$ \\
\hline Depth (cm) & $0-23$ & $23-64$ & $64-130$ & $130-150$ \\
\hline Clay (\%) & 7 & 6 & 6 & 5 \\
\hline Slime (\%) & 34 & 35 & 37 & 51 \\
\hline Sand (\%) & 59 & 59 & 57 & 44 \\
\hline Texture & $\begin{array}{c}\text { Sandy } \\
\text { loam }\end{array}$ & $\begin{array}{c}\text { Sandy } \\
\text { loam }\end{array}$ & $\begin{array}{c}\text { Sandy } \\
\text { loam }\end{array}$ & $\begin{array}{c}\text { Silty } \\
\text { loam }\end{array}$ \\
\hline Organic Matter \% & 1.1 & 0.5 & 0.3 & 0.2 \\
\hline Organic Carbon (\%) & 0.7 & 0.3 & 0.2 & 0.1 \\
\hline Total Nitrogen (\%) & 0.1 & 0.1 & 0 & 0 \\
\hline Relation C/N & 7 & 4 & 6 & 6 \\
\hline Phosphorus (p.p.m) & 0.9 & 2 & 1 & 1 \\
\hline CO ${ }_{3}$ Ca (\%) & 0 & 0 & 3.1 & 2.3 \\
\hline pH & 7.3 & 8 & 8.1 & 8 \\
\hline Calcium (meq/100 g) & 6.9 & 8.3 & - & - \\
\hline Magnesium (meq/100 g) & 1.2 & 1.2 & - & - \\
\hline Sodium (meq/100 g) & 0.2 & 0.4 & 0.5 & 1.1 \\
\hline Potassium (meq/100 g) & 0.9 & 0.6 & 0.6 & 0.5 \\
\hline CEC (meq/100 g) & 8.7 & 9.6 & 8.6 & 8.1 \\
\hline
\end{tabular}

Source: Angueira 2015.

\section{Quantified Net Aerial Primary Productivity}

On April $15^{\text {th }} 2018$, two commercial varieties of alfalfa, totally randomized design in $1.5 \mathrm{~m}^{2}$ plots with eight replications per variety ${ }^{-1}$, were implanted (Medicago sativa L.): G969 (www.gapp.com.ar) and Magna 901 (www.forratec.co m.ar). Both varieties belong to latency Group 9. The average density effectiveness was 350 plants per square meter. To minimize the factors affecting pasture biomass productivity and, consequently, the RUE (Monteith 1977) they were irrigated and fertilized while sowing with $100 \mathrm{~kg} \mathrm{ha}^{-1}$ of NPK (16.7.15). Monthly post-harvest irrigation of approximately $\sim 50 \mathrm{~mm}^{\text {irrigation }}{ }^{-1}$ was carried out. The green biomass or the net aerial primary productivity of each variety was harvested and weighed at the preflowering stage, and dried afterwards. Annual Net Aerial Primary Productivity of each variety was temporarily integrated and expressed in grams of dry matter per square meter $\left(\mathrm{g} \mathrm{dm} \mathrm{m}^{-2}\right)$. The means of the NAPP (hopes) between varieties (distributions) were evaluated using the T-test for independent samples (Di Rienzo et al. 2011). 


\section{Camera Technical Programming and Photography}

The images were obtained using a D7100 Nikon Digital Reflex Camera (Nikon Corporation, Tokyo, Japan) with a built-in CMOS image sensor of $23.5 \mathrm{x}$ $15.6 \mathrm{~mm}, 24.1 \mathrm{real}$ megapixels, an AF-S NIKKOR lens of $18-300 \mathrm{~mm} \mathrm{f} / 3.5-5.6 \mathrm{G}$ EDVR. The size of the selected photogram was $2.304 \times 1,536$ pixels in RAW format (Nikon Electronic Format), 14 bit depth, 24 bit RGB resolution (Ahrends et al. 2009). The camera was set up in automatic mode and an ISO 200 sensibility (Sakamoto et al. 2012).

The camera was geometrically set up onto a vertical tripod using bubble levels and angle graduation at $1 \mathrm{~m}$ above top of the canopy; the sensor was oriented to each plot center with a $0^{\circ}$ inclination angle (Tiedemann 2019) (Figure 2). The images were shot previous to harvest in cloud-free days at approximately solar noon between 10.00 AM and 2.00 PM (Inoue et al. 2015). The white balance of the images was adjusted using the $18 \%$ Gray Balance reflectance card (X-Rite corporation) placed at the central area of every plot (Inoue et al. 2015) (Figure 2).

\section{Image Processing and Digitization}

The calibration of the camera sensor was done using a calibration profile of DGN sensors generated from a standard color reference image Color Checker Passport (X-Rite, Incorporated).

All the images were linearly adjusted in spectral terms using the sensor calibrating profile (DGN), the Adobe Camera Raw software and saved as a TIFF (Tagged Image File Format) document standardized at 8 bit (Min 0; Max 255). The images were classified using the IsoData classifier available in the ImageJ software (Ferreira and Rasband 2016), assigning value one (1) to the green aerial forage biomass, i.e. the photosynthetically active vegetation (Baret et al. 2010), and zero (0) to the remainder background. From the resulting binary image, digital numbers were extracted using the digital sampling polygon (Sonnetag et al. 2011) (Figure 2).

Figure 2. Top: A) RGB Image at $0^{\circ}$ and $18 \%$ Gray Balance Reflectance Card B) Binary Image of A. Bottom: Red, Green and Blue Bands with Sampling Vectors (Red)

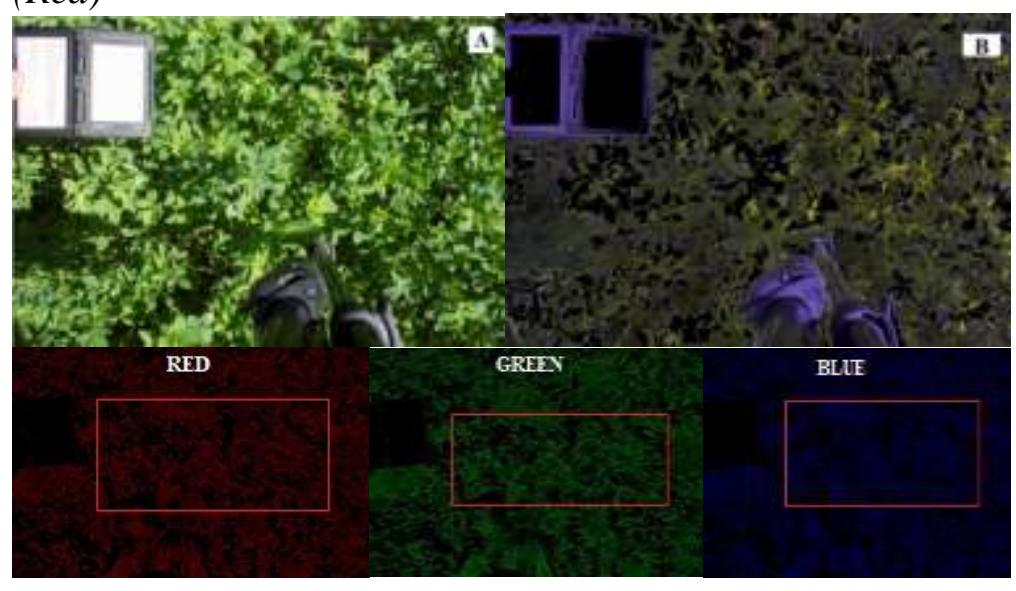




\section{The Red Vegetation Index}

The digital number of the RGB images was strongly influenced by the scene lighting. In order to suppress such an effect, a non-linear transformation of RGB to the $r, g$ and $b$ color coordinates (Gillespie et al. 1986, Woebbecke et al. 1995) was made. The chromatic coordinates $r, g$ and $b$ were obtained from equation 1:

$r=R^{*} / R^{*}+G^{*}+B^{*}, \quad g=G^{*} / R^{*}+G^{*}+B^{*}, \quad b=B^{*} / R^{*}+G^{*}+B^{*}$

where $\mathrm{R}^{*}, \mathrm{G}^{*}$ and $\mathrm{B}^{*}$ stand for the normalized $\mathrm{RGB}$ values $(0-1)$ defined as $\mathrm{R}^{*}=$ $\mathrm{R} / \mathrm{Rm} ; \mathrm{G}^{*}=\mathrm{G} / \mathrm{Gm} ; \mathrm{B}^{*}=\mathrm{B} / \mathrm{Bm}$, being $\mathrm{R}, \mathrm{G}$ and $\mathrm{B}$ the digital levels of the photosynthetically active vegetation of the study area, respectively, whereas $\mathrm{Rm}=$ $\mathrm{Gm}=\mathrm{Bm}=255$ were the tonal maximum value of the $(8 \mathrm{bit})$ primary colors (Gillespie et al. 1986; Woebbecke et al. 1995). In this study, the red color coordinate was used as the Red Vegetation Index (Tucker 1979).

\section{The Predicted Net Aerial Primary Productivity}

Many studies analyzed the direct relationship between the Normalized Difference Vegetation Index (NDVI) and the NAPP (Tucker 1979) expressed by equation 2 as:

$$
\mathrm{NAPP}_{\text {Predicted }}\left(\mathrm{g} \mathrm{dm} \mathrm{m}^{-2}\right)=\varepsilon^{*} \sum \mathrm{NDVI}_{\mathrm{ij}}
$$

By replacing the Normalized Difference Vegetation Index in Equation 2 by the Red Vegetation Index, Equation 3 results as:

$$
\mathrm{NAPP}_{\text {Predicted }}\left(\mathrm{g} \mathrm{dm} \mathrm{m}^{-2}\right)=\varepsilon^{*} \sum \mathrm{VI} \mathrm{Red}_{\mathrm{ij}}
$$

where $i$ stands for the integrated Red Vegetation Index of each cutting and variety of the growth season $j$ (i.e., between April 2018 and February 2019).

The values for the Radiation Use Efficiency $(\varepsilon)\left(\mathrm{g} \mathrm{Mj}^{-1}\right)$ in the study area are scarce because they were obtained for each variety using the Monteith's Model (1997) of Equation 4:

$$
\mathcal{E}\left(\mathrm{g} \mathrm{Mj}^{-1}\right)=\mathrm{NAPP}_{\text {Quantified }}\left(\mathrm{g} \mathrm{m}^{-2}\right) / \operatorname{PAR}\left(\mathrm{Mj} \mathrm{m}^{-2}\right)
$$

where NAPP stands for the quantified aerial biomass productivity, annually integrated for each replicate and variety. The annual average incident solar radiation over the study area was obtained from maps developed by Righini and Grossi Gallegos (2011). Photosynthetically active incident radiation (PAR) over the foliage is considered a constant fraction of $48 \%$ of incident radiation on the border of the atmosphere (Fensholt 2003). 


\section{The Quantified vs. the Predicted NAPP Relationship}

The quantified NAPP (dependent variable $y$ ) and the predicted NAPP (independent variable $x$ ) were related by means of the simple linear regression method $(\alpha 0.05)$. The lineal models were tested based on the best adjustment of the coefficient of determination (Di Rienzo et al. 2011).

\section{Results}

\section{Net Aerial Primary Productivity of the Varieties}

Seven harvests of each alfalfa variety were made between September 15, 2018 and February 4, 2019. Significant differences were not found in the NAPP between varieties $(T=0.92 ; p>0.05)$. The average NAPP of the G969 variety was $1564 \mathrm{~g} \mathrm{dm} \mathrm{m}^{-2}$ while that of the M901variety was $1636 \mathrm{~g} \mathrm{dm} \mathrm{m}^{-2}$. The NAPP of the G969 variety obtained in this study fluctuates in the range of the average values obtained for the same variety by Cornachione (2018) at Estacion Experimental Agropecuaria Santiago del Estero of Instituto Nacional de Tecnología Agropecuaria (EEA INTA SDE) in the following periods: 2014/2015 $=2157 \mathrm{~g} \mathrm{dm} \mathrm{m}^{-2}, 2015 / 2016=1802 \mathrm{~g} \mathrm{~ms} \mathrm{~m}^{-2}, 2016 / 2017=1926 \mathrm{~g} \mathrm{dm} \mathrm{m}^{-2}$ and $2017 / 2018=862 \mathrm{~g} \mathrm{dm} \mathrm{m}^{-2}$.

In the province of Cordoba, Argentina, the NAPP for the G969 variety estimated by Arolfo and Olivo (2018) was the following: 2014/2015 = $1344 \mathrm{~g} \mathrm{dm}$ $\mathrm{m}^{-2}, 2015 / 2016=1588 \mathrm{~g} \mathrm{~ms} \mathrm{~m}^{-2}$ and $2016 / 2017=919 \mathrm{~g} \mathrm{dm} \mathrm{m}^{-2}$. Similarly, Gallego et al. (2018) determined that the NAPP of the G969 variety was higher than $2000 \mathrm{~g} \mathrm{dm} \mathrm{m}^{-2}$ in the irrigated valleys of Rio Negro, Southern Argentina.

The EEA INTA SDE's network of cultivars did not report yield results of the M901 variety in the periods analyzed.

However, the NAPP obtained in this study of the M901 variety $(1636 \mathrm{~g} \mathrm{dm}$ $\mathrm{m}-2$ ) is in the range of average values of alfalfa varieties determined by the EEA INTA SDE. The average NAPP values estimated in the periods 2014/2018 were as follows: $2014 / 2015=2222 \mathrm{~g} \mathrm{dm} \mathrm{m}^{-2}, 2015 / 2016=1884 \mathrm{~g} \mathrm{~ms} \mathrm{~m}^{-2}, 2016 / 2017=$ $1980 \mathrm{~g} \mathrm{dm} \mathrm{m}^{-2}$ and 2017/2018 $=980 \mathrm{~g} \mathrm{dm} \mathrm{m}^{-2}$ (Cornachione 2018). Otero and Castro (2019) reported that the seasonal NAPP of intermediate-latency alfalfa in the period 1997/2011 in the Southeast of Uruguay was distributed as follows: Autumn $=3.902 \mathrm{~g} \mathrm{dm} \mathrm{m}^{-2}$, Winter $=1.872 \mathrm{~g} \mathrm{dm} \mathrm{m}^{-2}$, Spring $=4.024 \mathrm{dm} \mathrm{m}^{-2}$ and Summer $=5.381 \mathrm{dm} \mathrm{m}^{-2}$.

\section{Radiation Use Efficiency $(\varepsilon)$}

The average Radiation Use Efficiency of the G969 variety was $\varepsilon=0.56 \mathrm{~g} \mathrm{Mj}^{-1}$, being the maximum $\varepsilon=0.64 \mathrm{~g} \mathrm{Mj}^{-1}$ and the minimum $=0.43 \mathrm{~g} \mathrm{Mj}^{-1}$. The average Radiation Use Efficiency of the M901 variety was $\varepsilon=0.58 \mathrm{~g} \mathrm{Mj}^{-1}$, being the maximum $\varepsilon=0.66 \mathrm{~g} \mathrm{Mj}^{-1}$ and the minimum $=0.51 \mathrm{~g} \mathrm{Mj}^{-1} . \varepsilon$ values locally 
obtained become relevant since this variable creates greater uncertainty when estimating the NAPP using the Monteith model (Fensholt et al. 2003).

Pereyra et al. (2019) determined the $\varepsilon=0.83 \mathrm{~g} \mathrm{Mj}^{-1}$ of the Mayaco variety latency 7 in the city of Rio Cuarto, Cordoba, Argentina.

In turn, Akmal et al. (2011) found significant differences in the Radiation Use Efficiency of fifteen alfalfa lines. They observed that alfalfa line Flewish-pop was a high resource capturing with $0.20 \mathrm{~g} \mathrm{dm} \mathrm{Mj}^{-2}$ PAR absorbed among the other line when compared in the group, followed by line Gramma- 2 with about $0.18 \mathrm{~g} \mathrm{dm}$ $\mathrm{Mj}^{-2}$ PAR absorbed. The lowest RUE was recorded for No. 12-991 which was approximately $0.03 \mathrm{~g} \mathrm{dm} \mathrm{Mj}^{-2}$ PAR absorbed.

According to Druille et al. (2019), their objective was to quantitatively synthesize, through a meta-analysis, the variation of RUE of forage resources and its main controls. They gathered 496 RUE values and assessed their variation according to genotype, resource availability and phonological stage. Mean RUE was $1.93 \pm 1.2 \mathrm{~g} \mathrm{dm} \mathrm{Mj}^{-2}$ PAR absorbed. This large variability implies a challenge to select RUE values as input to estimate productivity through plant-growth models, such as those based on remote sensing, but also highlight the margin for increasing RUE through breeding and management practices.

\section{The Quantified-Predicted NAPP Relationship}

Significant direct relationships were found in the correlations between the quantized NAPP and the predicted one by the Red Vegetation Index for each variety (Figures 3 and 4). The resulting models are introduced by Equations 5 and 6 below:

$$
\begin{array}{ccc}
\mathrm{NAPP}_{\mathrm{G} 969}=506.06 * \mathrm{x}-343.25 & \left(\mathrm{R}^{2}=0.88 ; \mathrm{p}<0.001\right) & (5) \quad \text { (Figure 3), } \\
\mathrm{NAPP}_{\mathrm{M} 901}=420.28 * \mathrm{x}+37.82 & \left(\mathrm{R}^{2}=0.98 ; \mathrm{p}<0.001\right) & (6) \quad(\text { Figure 4) }
\end{array}
$$

Figure 3. The G969 Variety Linear Regression Model between the Estimated and the Predicted NAPPs $\left(\mathrm{gdm} \mathrm{m}^{2}\right)$

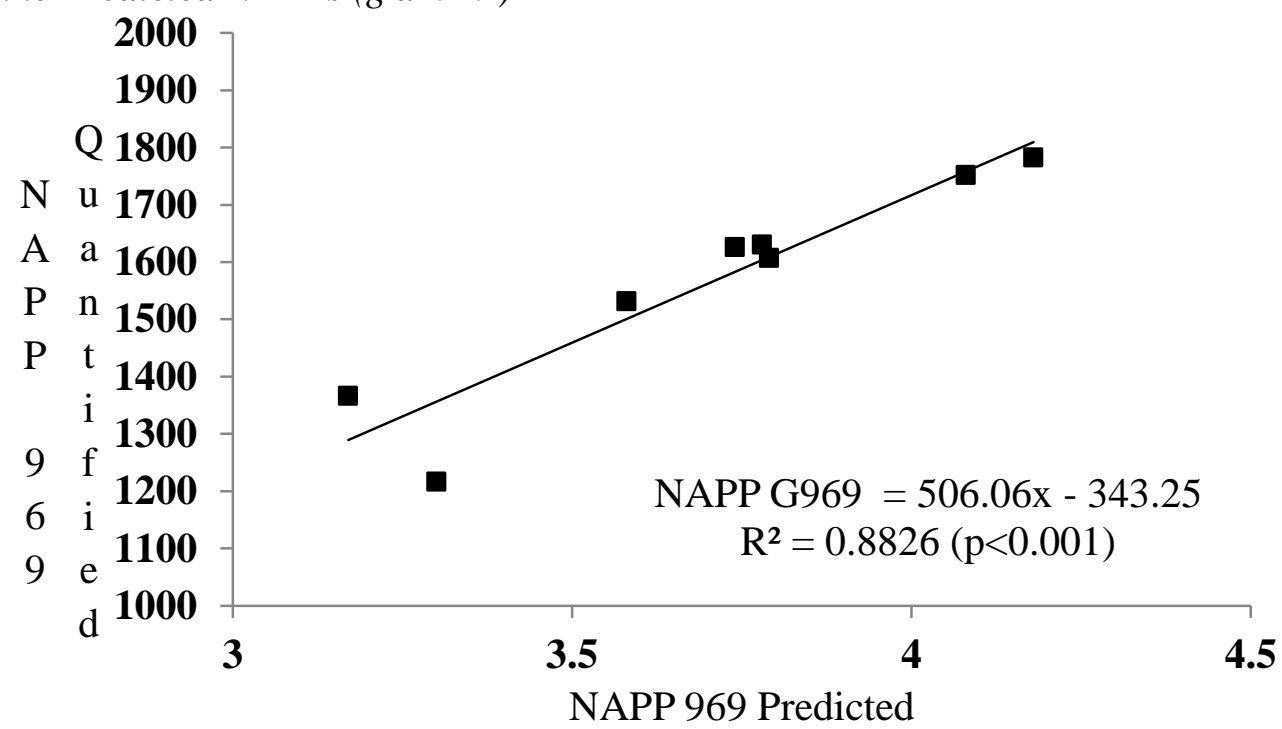


Figure 4. The M901 Variety Linear Regression Model between the Estimated and the Predicted ( $\mathcal{E}^{*} I V$ Red) NAPPS $\left(g d m m^{2}\right)$

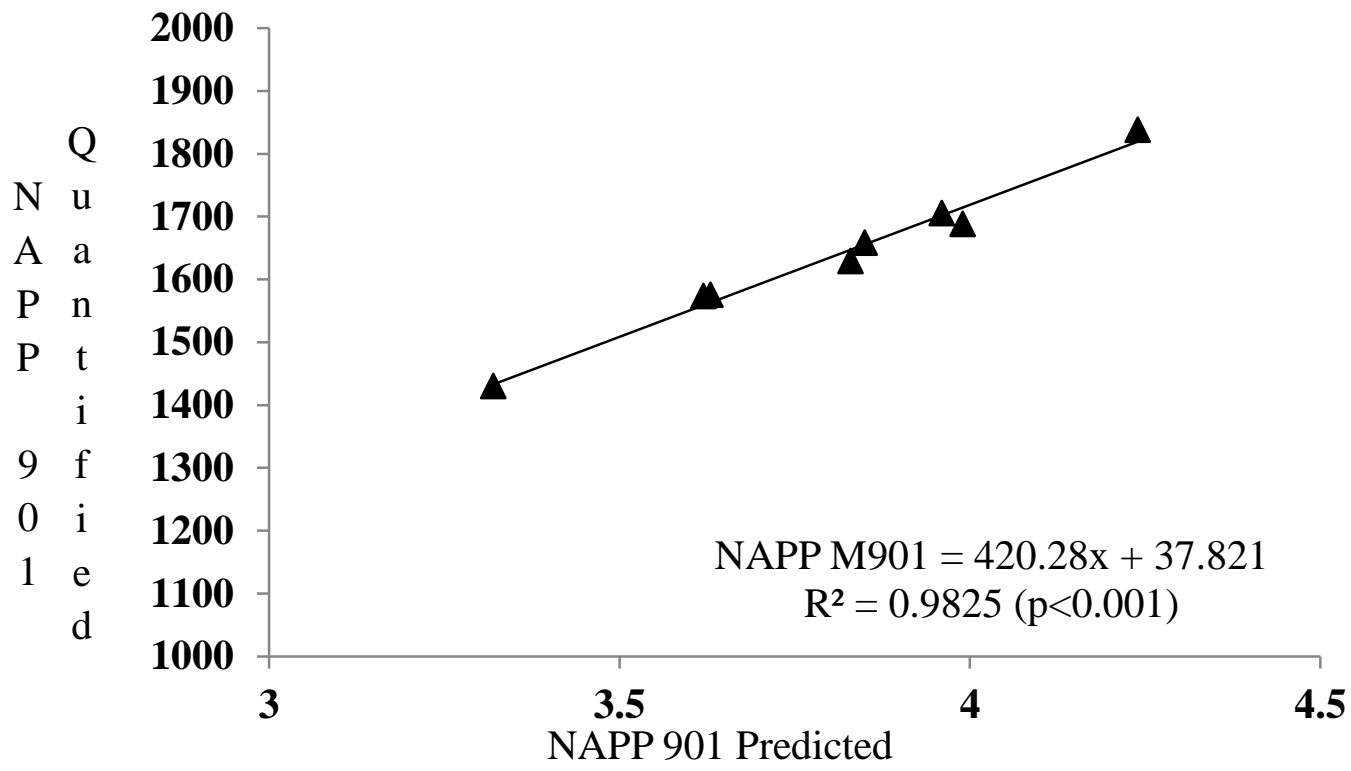

In preliminary studies, Tiedemann (2018a) found significant inverse relationships $\left(\mathrm{R}^{2}=0.81, \mathrm{r}=-0.92 ; \mathrm{p}<0.01\right)$ between the integrated NAPP of the G969 alfalfa and the RGB Vegetation Index (i.e., Red, REI, T and SUM).

Grüner et al. (2019) developed prediction models for dry matter yield in temperate grassland based on the canopy height data generated by RGB imaging. The multi-temporal study compared the remote sensing technique with two conventional methods, i.e., destructive biomass sampling and ruler height measurements in two legume-grass mixtures with red clover (Trifolium pratense L.) and lucerne (Medicago sativa L.) in combination with Italian ryegrass (Lolium multiflorum Lam.). The results showed that yield prediction by RGB imaging provided similar accuracies across all treatments $\left(\mathrm{R}^{2}=0.59-0.81\right)$ as the ruler height measurements $\left(\mathrm{R}^{2}=0.58-0.78\right)$. Bendig et al. (2014) estimated aboveground biomass and fresh and dry biomass on a summer barley test site with 18 cultivars and two nitrogen (N)-treatments using the plant height from crop surface models. The crop surface models were derived from red, green, blue (RGB) images. Five models for above-ground fresh and dry biomass estimation were tested by cross-validation. Modelling biomass between different $\mathrm{N}$-treatments for fresh biomass produced the best results $\left(\mathrm{R}^{2}=0.71\right)$. Schirrmann et al. (2016) monitored the biophysical parameters and nitrogen status in wheat crops with lowcost imagery. The correlations between the biophysical parameters and image variables were highly significant, the regression models calculated with the principal components of the image variables yielded $R^{2}$ values between 0.70 and 0.97 .

Lussem et al. (2018) evaluated the robustness of RGB-based vegetation indices to estimate dry matter forage yield on a recently established experimental grassland site in Germany. They selected RGB-based vegetation indices which were tested to predict dry matter yield and compared to three indices from the 
visible to near-infrared domain calculated from spectroradiometer measurements. The results showed a correlation of forage yield with RGB-based VIs such as the NGRDI index (NGRDI = green-red/green+red) (developed by Tucker 1979) with $\mathrm{R}^{2}$ values of 0.62 . Hunt et al. (2005) observed a linear correlation of NGRDI with alfalfa, corn, and soy biomass, but also observed saturation effects of the predictor variable for higher biomass yields.

Similarly, Fernandez et al. (2019) evaluated the capacity of vegetation indices formulated using blue (B), green $(\mathrm{G})$, red $(\mathrm{R})$ and near-infrared $(\mathrm{NIR})$ bands obtained with a consumer grade camera to assess wheat $\mathrm{N}$ status. RGB indices and NDVI obtained with a consumer-grade camera showed comparable capacity at assessing chlorophyll content and predicting both crop biomass and grain production at harvest as those obtained with a spectroradiometer. The RGB indices and NDVI were found to be related to both crop biomass and grain production at harvest $(r>0.80, \mathrm{p}<0.01)$.

Tiedemann $(2018 \mathrm{~b})$ found significant direct relationships $(\mathrm{p}<0.01)$ between the NAPP of wheat varieties and the Total and Red indices; the $\mathrm{R}^{2}$ varied between 0.92 and 0.96. Following the same study line, Tiedemann (2019) detected significant $(\mathrm{p}<0.01)$ direct relationships between the Red, REI, T and SUM Vegetation Indices taken at $0^{\circ}$ and $45^{\circ}$ and the NAPP of wheat varieties. The resulting linear models at a $0^{\circ}$ angle showed an $\mathrm{R}^{2}$ that ranged from 0.75 to 0.67 , while at $45^{\circ}$, the $\mathrm{R}^{2}$ varied between 0.67 and 0.70 .

\section{Discussion}

The average NAPP obtained from both varieties oscillates in the range of the NAPP average values of 27 alfalfa varieties in the 8,9 and 10 latency groups (recommended for the Argentine Northwest) determined by the EEA INTA SDE. The average NAPP during 2010/2018 was $1995.9 \mathrm{~g} \mathrm{dm} \mathrm{m}^{-2}$ (Cornachione 2018). It should be noted that alfalfa cultivars yield has been severely affected in recent decades by extreme climatic anomalies, since the genotype/environment interaction conditioned the expression of cultivars, especially cultivars without winter dormancy (Spada 2007).

Since the Radiation Use Efficiency $\mathcal{E}$ values of alfalfa (Medicago sativa L.) are scarce in the region, the results obtained here become relevant since, in accordance with Baret et al. (2010), they allow to lower uncertainty in the generation of predictive models. According to Collino et al. (2007) variations of $\varepsilon$ are to be attributed to factors such as variety, radiation and temperature regimes, direct-diffuse radiation rate and differences in the partition between foliage and storing organs (crown and roots). In turn, Druille et al. (2019) informed that the $\varepsilon$ values mostly respond to the genotype and directly or indirectly to resource management and availability. Brown et al. (2006) quantified the influence of the seasonal variation on the solar radiation, temperature and the biomass partition of irrigated alfalfa and found a lineal relationship between the NAPP of the alfalfa $\left(\mathrm{R}^{2}=0.93\right)$ and the total intercepted radiation, the $\mathcal{E}$ ranged between $0.29 \mathrm{~g} \mathrm{Mj}^{-1}$ and $1.09 \mathrm{~g} \mathrm{Mj}^{-1}$. The authors concluded that the NAPP is highly affected by the 
variation of the incident solar radiation (seasonality) and by the air temperature in temperate environments. In this sense, Bat-Oyun et al. (2012) determined for natural pastures in semiarid settings a wide range of $\mathcal{E}\left(0.23 \mathrm{~g} \mathrm{Mj}^{-1}-1.06 \mathrm{~g} \mathrm{Mj}^{-1}\right)$ that was affected by water and thermal stress, together with a maximum $\varepsilon$ value of $2.34 \mathrm{~g} \mathrm{Mj}^{-1}$ without thermal and water stress. At the same time Garbulsky (2010) concluded that the spatial variability of the $\varepsilon$ can be better explained by the annual precipitation than by the type of vegetation.

At a regional level, Collino et al. (2005) determined in Cordoba, Argentina, that the $\varepsilon$ for the Monarca SP INTA crop (group 8 of dormancy) was of $0.81 \mathrm{~g} \mathrm{Mj}^{-}$ ${ }^{1}$ in fall, $0.62 \mathrm{~g} \mathrm{Mj}^{-1}$ in winter, $1.28 \mathrm{~g} \mathrm{Mj}^{-1}$ in spring and $1 \mathrm{~g} \mathrm{Mj}^{-1}$ in summer. The $\varepsilon$ of the Victoria SP INTA crop (group 6 of dormancy) fluctuated between $0.6 \mathrm{~g} \mathrm{Mj}^{-}$ ${ }^{1}$ and $1.3 \mathrm{~g} \mathrm{Mj}^{-1}$, decreased linearly below $21.3^{\circ} \mathrm{C}$ and stabilized in 1.3 within an average range of optimal temperatures of $21.3{ }^{\circ} \mathrm{C}$ and $26.5{ }^{\circ} \mathrm{C}$. The authors concluded that such a wide range of $\mathcal{E}$ occurred because of the high variation in the annual temperatures and the distribution of photo-assimilates. Pece and Cangiano (2002) using a similar crop, found the same trend in the southeast of Buenos Aires, Argentina, though with values of $\mathcal{E}$ oscillating between $1.1 \mathrm{~g} \mathrm{Mj}^{-1}$ and $1.97 \mathrm{~g} \mathrm{Mj}^{-1}$.

Because of the arid conditions of the study area, and of NW Argentina in general, the edaphic water availability appears as the limiting factor; without such a limiting factor, all the varieties of alfalfas respond with a high $\varepsilon$ in both fall and summer. However, in accordance with Collino et al. (2007), the $\varepsilon$ is affected by low temperatures and photo-assimilates mobility in fall and winter.

The models found had a high ability to predict the NAPP of both varieties, the coefficient of determination $\left(\mathrm{R}^{2}\right)$ of both models is high (Equations 5 and 6), however, that of the M901variety is much higher. What would be the reason for this difference if both varieties were treated under similar environmental conditions (irrigation, fertilization, seasonality, sanity and management)? At the time the photogram was shot, the solar lighting geometry, the storage format of the photogram, the camera nadir position, the adjustment of the white balance of the images, the sensor calibration, and the methodology in the preparation of the Index were considered. Therefore, such difference should be related to the combined effects of the whole-canopy structure of the varieties, such as foliage geometry and leaves distribution, stem characteristics, that affect the patterns of scattering and absorption and consequently the Vegetation Index (Ollinger 2011, Grüner et al. 2019, Biriukova et al. 2020). In this sense and according to their respective producers, the M901variety has a semi-erect growth habit while the G969 shows an erect one, and hence both varieties use the space in a different way. The semierect M901 variety shows a green leaf area larger than that of the erect variety when the photogram is taken at a $0^{\circ}$ angle. Results of yield prediction by RGB imaging obtained by Grüner et al. (2019) demonstrated an improved robustness when increased canopy height variability occurred due to extreme weather conditions. It became apparent that morphological characteristics of clover-based canopies $\left(R^{2}=0.75\right)$ allow a better remotely sensed prediction of total annual yield than for lucerne-grass mixtures $\left(\mathrm{R}^{2}=0.64\right)$, and that these crop-specific models cannot be easily transferred to other grassland types. In turn, Inostroza et al. (2018) found significant inverse relationships with the Lab-b $(r=0.56, p<0.001)$, HUE ( $r$ 
$=0.58, \mathrm{p}<0.001)$, Luv-v $(\mathrm{r}=0.55, \mathrm{p}<0.001)$ and green area $(\mathrm{r}=0.36, \mathrm{p}<0.01)$ indices when evaluating the phenotypical relationship between the Vegetation Indices derived from the RGB digital camera and the NAPP of sixty-three populations of alfalfa. The authors preliminarily concluded that the RGB digital camera-derived Vegetation Indices are phenotypically associated to the NAPP. In the same way, Mizunuma et al. (2014) recommend using hue as a colour index for tracking different stages of leaf development. However, it should be noted that Stevens et al. (2007) do not recommend utilizing indices derived from the conversion to other values of color in the space as HSB (hue, saturation and brightness) because of their high inaccuracy.

\section{Conclusions}

The NAPP values obtained for both varieties represent an original contribution to this field of study, especially the M901 variety NAPP.

The values for the Radiation Use Efficient $\varepsilon$ of the alfalfa varieties under study, determined at local level, gain relevance due to the absence of locally estimated values. These reduce uncertainty when predictive models of productivity are generated.

The net aerial primary productivity (NAPP) of alfalfa varieties can be quantified in situ in a non-destructive manner using the Red Vegetation Index. The strength of the Index lies in the rigorous methodology used for its creation and because it was derived from a reflex RGB digital camera.

\section{References}

Ahrends HE, Etzold S, Kutsch WL, Stoeckli R, Bruegger R, Jeanneret F et al. (2009) Tree phenology and carbon dioxide fluxes: use of digital photography for process-based interpretation at the ecosystem scale. Climate Research 39(3): 261-274.

Akmal M, Farid U, Aasim M, Farhatullah, Rasiuddin (2011) Crop growth in early spring and radiation use efficiency in alfalfa. Pakistan Journal of Botany 43(1): 635-641.

Angueira C (2015) Relevamiento de suelos utilizando las nuevas técnicas de geomática: un caso en Santiago del Estero, Argentina. (Soil survey using new geomatics techniques: a case in Santiago del Estero, Argentina). PhD Thesis. Spain: Universidad de Córdoba.

Arolfo V, Olivo S (2018) Avances en alfalfa. Ensayos Territoriales. (Advances in alfalfa. Territorial trials). In V Arolfo, A Odorizzi (eds.), Red de evaluacion de cultivares. Argentina: Ediciones INTA.

Baret F, de Solan B, Lopez-Lozano R, Kay Weiss M (2010) GAI estimates of row crops from downward looking digital photos taken perpendicular to rows at $57.5^{\circ}$ zenith angle: Theoretical considerations based on 3D architecture models and application to wheat crops. Agricultural and Forest Meteorology 150(11): 1393-1401.

Bat-Oyun T, Shinoda M, Tsubo M (2012) Effects of water and temperature stresses on radiation use efficiency in a semi-arid grassland. Journal of Plant Interactions 7(3): 214-224. 
Bendig J, Bolten A, Bennertz S, Broscheit J, Eichfuss S, Bareth G (2014) Estimating Biomass of Barley Using Crop Surface Models Derived from UAV-Based RGB Imaging. Remote Sensing 6(11): 10395-10412.

Biriukova K, Celesti M, Evdokimova A, Pacheco-Labrador J, Julitta T, Migliavacca M et al. (2020) Effects of varying solar-view geometry and canopy structure on solarinduced chlorophyll fluorescence and PRI. International Journal of Applied Earth Observation and Geoinformation 89(Jul): 102069.

Brown HE, Moot DJ, Teixeira EI (2006) Radiation use efficiency and biomass partitioning of lucerne (Medicago sativa L.) in a temperate climate. European Journal of Agronomy 25(4): 319-327.

Collino DJ, Dardanelli JL, De Luca, MJ, Racca RW (2005) Temperature and water availability effects on radiation and water use efficiencies in alfalfa (Medicago sativa L.). Australian Journal of Experimental Agriculture 45(4): 383-390.

Cornachione M (2018) Avances en alfalfa. Ensayos Territoriales. (Advances in alfalfa. Territorial trials). In V Arolfo, A Odorizzi (eds.), Red de evaluacion de cultivares. Argentina: Ediciones INTA.

Costa L, Nunes L, Ampatzidis Y (2020) A new visible band index (vNDVI) for estimating NDVI values on RGB images utilizing genetic algorithms. Computers and Electronics in Agriculture 172(May): 105334.

Di Rienzo JA, Casanoves F, Balzarini MG, Gonzalez L, et al. (2011) Grupo InfoStat, FCA. Argentina: Universidad Nacional de Córdoba.

Druille M, Yarzabal M, Oesterheld M (2019) Radiation use efficiency of forage resources: a meta-analysis. Agronomy Journal 111(4): 1-9.

Fensholt R (2003) Assessment of primary production in semi-arid environment from satellite data. Exploiting capabilities of new sensors. PhD Thesis. Copenhagen, Denmark: Institute of Geography, University of Copenhagen.

Fernandez E, Gorchs G, Serrano L (2019) Use of consumer-grade cameras to assess wheat N status and grain yield. PLoS ONE 14(2): e0211889.

Ferreira T, Rasband W (2016) ImageJ user guide. Retrieved from: http://imagej.nih.gov. [Accessed 12 October 2020.]

Gallego J, Miñón D, Spada M, Basigalup D, Romero L, Mattera J, et al. (2018) Productive behavior of alfalfa (Medicago sativa L.) in Argentina different regions: cultivars evaluation networks. In Proceedings of the Second World Alfalfa Congress Crops, 11-14 November 2018 Cordoba, Argentina.

Garbulsky MF (2010) On the remote sensing of the radiation use efficiency and the gross primary productivity of terrestrial vegetation. $\mathrm{PhD}$ Thesis. Barcelona, Spain: Universitat Autonoma de Barcelona.

Ge Y, Bai G, Stoerger Ge, Schnable JC (2016) Temporal dynamics of maize plant growth, water use, and leaf water content using automated high throughput RGB and hyperspectral imaging. Computers and Electronics in Agriculture 127(Sep): 625-632.

Gillespie AR, Kahle AB, Kahle AB, Walker RE (1986) Color enhancement of highly correlated images. I. Decorrelation and HSI contrast stretches. Remote Sensing of Environment 20(3): 209-235.

Gitelson AA, Kaufman YJ, Stark R, Rundquist D (2002) Novel Algorithms for Remote Estimation of Vegetation Fraction. Remote Sensing of Environment 80(1): 76-87.

Grüner E, Astor T, Wachendorf M (2019) Biomass prediction of heterogeneous temperate grasslands using an SfM approach based on UAV imaging. Agronomy 9(2): 54.

Hunt ER, Cavigelli M, Daughtry C, McMurtrey J, Walthall C (2005) Evaluation of digital photography from model aircraft for remote sensing of crop biomass and nitrogen status. Precision Agriculture 6(4): 359-378. 
Inostroza L, Espinoza S, Ovalle C, Barahona V, Humphries A, Del Pozo A (2018) RGBimages derived vegetation indices for estimating alfalfa dry matter production in rainfed Mediterranean environments. In Proceedings of the Second World Alfalfa Congress Crops, 11-14 November 2018 Cordoba, Argentina.

Inoue T, Nagai S, Kobayashi H, Koizumi H (2015) Utilization of ground-based digital photography for the evaluation of seasonal changes in the aboveground green biomass and foliage phenology in a grassland ecosystem. Ecological Informatics 25(9): 1-9.

Jáuregui JM, Delbino F, Ballanti S, Bosio M, Brance MI, Iglesias B, et al. (2018) Use of Canopeo to determine light interception and yield of alfalfa (Medicago sativa L.). In Proceedings of the Second World Alfalfa Congress crops, 11-14 November 2018 Cordoba, Argentina.

Luca M (2007) Uso del agua y la radiación para producción de forraje. (Use of water and radiation for forage production). In D Basigalup (ed.), El cultivo de la Alfalfa. Argentina: Ediciones INTA.

Lussem U, Bolten A, Gnyp ML, Jasper J, Bareth G (2018) Evaluation of RGB-based vegetation indices from UAV imagery to estimate forage yield in grassland. The International Archives of the Photogrammetry, Remote Sensing and Spatial Information Sciences volume XLII-3. In ISPRS TC III Mid-term Symposium Developments, Technologies and Applications in Remote Sensing, 7-10 May, Beijing, China.

Mckinnon T, Hoff P (2017) Comparing RGB-based vegetation indices with NDVI for drone based agricultural sensing. Agribotix.

Mizunuma T, Mencuccini M, Wingate L, Ogee J, Nichol C, Grace J (2014) Sensitivity of colour indices for discriminating leaf colours from digital photographs. Methods in Ecology and Evolution 5(10): 1078-1085.

Monteith JL (1977) Climate and the efficiency of crop production in Britain. Philosophical Transactions of the Royal Society of London B 281(980): 277-294.

Ollinger SV (2011) Sources of variability in canopy reflectance and the convergent properties of plants. New Phytologist 189(2): 375-394.

Otero A, Castro M (2019) Variability of alfalfa (Medicago sativa L.) Seasonal forage production in the Southwest of Uruguay. Agrociencia Uruguay 23(1): 1-11.

Pece MA, Cangiano CA (2002) Tasa de acumulación de la biomasa aérea de alfalfa en respuesta a la radiación. (Accumulation rate of aerial biomass of alfalfa in response to radiation). In $25^{\circ}$ Congreso Argentino de Producción Animal 22(1): 120-121.

Pereyra T, Ohanian E, Salusso N (2019) Eficiencia en el uso de la radiación y el agua, en intercultivos de alfalfa (Medicago sativa L.) con sorgo sudan (Sorghum sudanense) y mijo perla (Pennisetum americanum). (Efficiency in the use of radiation and water, in intercropping of alfalfa (Medicago sativa L.) with Sudan sorghum (Sorghum Sudanense) and pearl millet (Pennisetum americanum). Archivos Latinoamericanos de Producción Animal 27(1-4): 13-19.

Przeszlowska A, Trlica MJ, Weltz MA (2006) Nearground remote sensing of green area index on the shortgrass prairie. Rangeland Ecology \& Management 59(4): 422- 430.

Righini R, Grossi Gallegos H. (2011) Mapa de energía solar colectada anualmente por un plano inclinado. Un ángulo optimo en la República Argentina. (Map of solar energy collected annually by an inclined plane. An optimal angle in Argentina). In IV Congreso Nacional y III Congreso Iberoamericano. Hidrógeno y Fuentes sustentables de Energía.

Sakamoto T, Gitelson AA, Nguy-Robertson AL, Arkebauer J, Wardlow BD, Suyker AE et al. (2012) An alternative method using digital cameras for continuous monitoring of crop status. Agricultural and Forest Meteorology 154-155(1): 113-126. 
Schirrmann M, Giebel A, Gleiniger F, Pflanz M, Lentschke J, Dammer K (2016) Monitoring agronomic parameters of winter wheat crops with low-cost UAV imagery. Remote Sensing 8(9): 706.

Sonnentag O, Detto M, Vargas R, Ryu Y, Runkle BRK, Kelly M et al. (2011) Tracking the structural and functional development of a perennial pepperweed (Lepidium latifolium L.) infestation using a multi-year archive of webcam imagery and eddy covariance measurements. Agricultural and Forest Meteorology 151(7): 916-926.

Spada MC (2007) Evaluación de cultivares y panorama varietal. (Evaluation of cultivars and varietal panorama). In DH Basigalup, EEA Manfredi (eds.), El Cultivo de la Alfalfa en la Argentina. Argentina: Ediciones INTA.

Stevens M, Parraga CA, Cuthill IC, Partridge JC, Troscianko TS (2007) Using digital photography to study animal coloration. Biological Journal of the Linnean Society 90(2): 211-237.

Tiedemann JL (2018a) Productividad de biomasa forrajera aérea integrada de alfalfa (Medicago sativa L) y sensores cercanos. (Integrated aerial forage biomass productivity of alfalfa (Medicago sativa L) and nearby sensors). In XIII Jornadas de Ciencia y Tecnología de las Facultades de ingeniería del NOA. 13-14 Sep, SDE.

Tiedemann JL (2018b) Productividad de biomasa forrajera aérea de variedades de trigo (Triticum aestivum L.) y su relación con coordenadas cromáticas derivadas de cámara digital. (Aerial forage biomass productivity of wheat varieties (Triticum aestivum L.) and its relationship with chromatic coordinates derived from digital cameras). Ecologia Aplicada 17(1): 61-68.

Tiedemann JL (2019) Índices $R G B$ derivados de cámara digital y su relación con la productividad primaria neta aérea de cultivares de trigo (Triticum aestivum L). (RGB indices derived from digital cameras and their relationship with the aerial net primary productivity of wheat cultivars (Triticum aestivum L)). Anales de CAI.

Tucker CJ (1979) Red and photographic infrared linear combinations for monitoring vegetation. Remote Sensing of Environment 8(2): 127-150.

Woebbecke DM, Meyer GE, Von Bargen K, Mortensen DA (1995) Color indices for weed identification under various soil, residue, and lighting conditions. Transactions of the ASAE 38(1): 259-269.

Zhao D, Starks PJ, Brown MA, Phillips WA, Coleman SW (2007) Assessment of forage biomass and quality parameters of bermudagrass using proximal sensing of pasture canopy reflectance. Grassland Science 53(1): 39-49. 
